\title{
Advances in mathematics education: new book series connected to ZDM-The International Journal on Mathematics Education
}

\author{
Gabriele Kaiser • Bharath Sriraman
}

Published online: 12 January 2010

(C) FIZ Karlsruhe 2010

A new monograph series "Advances in Mathematics Education" has just been established which builds on the tradition and history of the international journal "ZDMThe International Journal on Mathematics Education". One characteristic of ZDM since its inception in 1969 has been the publication of themed issues that aim to bring the stateof-the-art on central sub-domains within mathematics education. The published issues include a rich variety of topics and contributions that continue to be of relevance today. The newly established monograph series edited by Gabriele Kaiser and Bharath Sriraman aims to integrate, synthesize and extend papers from previously published themed issues of importance today, by orienting these issues towards the future state-of-the-art. The main idea is to move the field forward with a book series that looks to the future by building on the past by carefully choosing viable ideas that can fruitfully mutate and inspire the next generations. So, it is our attempt to create something new for the field by making useful combinations of existing ideas with those that are considered to be at the frontiers of the field of mathematics education research today, to carefully select from the past and cross-fertilize ideas across generations with the hope of producing something relevant, forward oriented, synthetic and innovative.

G. Kaiser $(\bowtie)$

Didactics of Mathematics, Faculty of Education,

University of Hamburg, Von-Melle-Park 8,

20146 Hamburg, Germany

e-mail: gabriele.kaiser@uni-hamburg.de

B. Sriraman

Department of Mathematical Sciences,

The University of Montana,

Missoula, MT 59812-0864, USA
The series is supported by an editorial board of internationally distinguished scholars, who bring in their long experience in the field as well as their expertise to this series. The members of the editorial board are: Ubiratan D’Ambrosio (Brazil), Miriam Amit (Israel), Jinfa Cai (USA), Helen Forgasz (Australia), and Jeremy Kilpatrick (USA).

The inaugural monograph has already been released in 2010 edited by Bharath Sriraman and Lyn English with the title "Theories of mathematics education: Seeking New Frontiers".

The first book in this series on Theories of Mathematics Education provides a prototype of the book series. Theories of Mathematics Education carries forward and consolidates the work and voices of four generations of mathematics education researchers. The book's inspiration lies in the work of Hans-Georg Steiner's (1928-2004) international study group called Theory of Mathematics Education (TME) which had held five international conferences until 1992, and offered a regular topic study group at the quadrennial International Congress of Mathematics Education (ICME) until the turn of the last century at which point activity seemed to cease. The editors of the book (Sriraman and English) revived the activity of this group at the 2005 Annual meeting of the International Group for the Psychology of Mathematics Education (IGPME) in Melbourne, in a research forum focussed on theories. Five years later, substantial work on theories has been accomplished by numerous groups and researchers around the world, in unexpected, surprising and fruitful directions such as complexity theory and the neurosciences. This includes sustained collaborative work by participants from the 2005 PME forum that resulted in two ZDM issues on theories in 2005 and 2006, in addition to work on theories at subsequent Congresses of the European Society for 
Mathematics Education (CERME), prominent among which is the work on "networking strategies" that produced a substantial ZDM issue (issue 2, 2008).

The "networking" approach aims to connect different theoretical approaches using several strategies. It rejects isolationistic tendencies of separating different theoretical approaches and bases its work on the assumption that the variety of different theoretical approaches and perspectives in mathematics education research served as a rich resource upon which the scientific community should build via layered connections between different theories. The intention is not to develop one grand unified theory, but to network local theories that deal with background theories, and use diverging conceptual systems for describing the same phenomena.

Another distinct feature of this book series is the usage of the ancient scholarly Chinese and Indian traditions of commentaries. As the Taoist scholar Guo Xiang (252-312 C.E.) and the Indian advaitist Shankara (788-820 C.E.) demonstrated, the purpose of a commentary is not only to elucidate ideas present in an original text, but also to philosophize and provide deeper meaning to older ideas, and we add to take them forward in ways not conceived of originally. This series and the present book strive to do so by soliciting commentaries from experts and novices. We find it particularly important to integrate newer voices, including those that have just entered the field, in order to prevent an orthodoxy seeping into the realm of ideas. In addition, prefaces to chapters set the stage for the motivation, purpose, and background of a given work.

The monograph consists of 19 parts on the following themes and contributors:

- Surveying Theories and Philosophies of Mathematics Education (Jeremy Kilpatrick; Bharath Sriraman, and Lyn English);

- Reflections on Theories of Learning (Bharath Sriraman, and Nick Haverhals; Paul Ernest; Simon Goodchild);

- On the Theoretical, Conceptual, and Philosophical Foundations for Research in Mathematics Education (Lyn English; Frank Lester; Guershon Harel);

- Theories of Mathematics Education: Is Plurality a Problem? (Norma Presmeg; Stephen Lerman; Eva Jablonka, and Christer Bergsten);

- Re-conceptualizing Mathematics Education as a Design Science (Lyn English; Richard Lesh, and Bharath Sriraman; Miriam Amit; Claus Michelsen; David Boote);

- The Fundamental Cycle of Concept Construction Underlying Various Theoretical Frameworks (Stephen Hegedus; John Pegg, and David Tall; Bettina Dahl);

- Symbols and Mediation in Mathematics Education (Stephen Hegedus; Luis Moreno-Armella, and Bharath Sriraman; Gerald Goldin);
- Problem Solving Heuristics, Affect, and Discrete Mathematics: A Representational Discussion (Gerald Goldin; Jinfa Cai);

- Problem Solving for the 21st Century (Jinfa Cai; Lyn English, and Bharath Sriraman; Peter Grootenboer; Alan Zollman);

- Embodied Minds and Dancing Brains: New Opportunities for Research in Mathematics Education (Layne Kalbfleisch; Stephen Campbell; Scott Makeig);

- DNR-Based Instruction in Mathematics as a Conceptual Framework (Luis Moreno-Armella; Guershon Harel; Bharath Sriraman, Hillary VanSpronsen, and Nick Haverhals);

- Appreciating Scientificity in Qualitative Research (Stephen Hegedus);

- Understanding a Teacher's Actions in the Classroom by Applying Schoenfeld's Theory Teaching-in-Context: Reflecting on Goals and Beliefs (Gerald Goldin; Günter Törner, Katrin Rolka, Bettina Rösken, and Bharath Sriraman; Dina Tirosh, and Pessia Tsamir);

- Feminist Pedagogy and Mathematics (Gabriele Kaiser; Judith Jacobs; Gilah Leder; Safure Bulut, Bekir Gür, and Bharath Sriraman; Güßbjörg Pálsdóttir, and Bharath Sriraman);

- Networking of Theories-An Approach for Exploiting the Diversity of Theoretical Approaches (Tommy Dreyfus; Angelika Bikner-Ahsbahs, and Susanne Prediger; Ferdinando Arzarello);

- Issues and Practices in Networking Theories (Susanne Prediger, and Angelika Bikner-Ahsbahs; Helga Jungwirth; Uwe Gellert; Tine Wedege);

- Complexity Theories and Theories of Learning: Literature Reviews and Syntheses (Richard Lesh; Andy Hurford);

- Knowing More Than We Can Tell (Bharath Sriraman; Nathalie Sinclair; David Pimm);

- Politicizing Mathematics Education: Has Politics Gone Too Far? Or Not Far Enough? (Bharath Sriraman, Matt Roscoe, and Lyn English; Keiko Yasukawa).

A review of the book is to appear in one of the next issues of ZDM-The International Journal on Mathematics Education.

The second monograph to appear in this series will be on "Early Algebraization: Cognitive, Curricular, and Instructional Perspectives" edited by Jinfa Cai and Eric Knuth. The third book will be edited by Helen Forgasz and Ferdinand Rivera with the title "Towards Equity: Gender, Culture, and Diversity".

The books will appear in 2010 and beginning of 2011 . 